\title{
Thyrotoxicosis with absence of clinical features of acromegaly in a TSH- and GH-secreting, invasive pituitary macroadenoma
}

\author{
Philip C Johnston, Amir H Hamrahian, Richard A Prayson', Laurence Kennedy and \\ Robert J Weil ${ }^{2,+}$
}

Department of Endocrinology, Diabetes and Metabolism, Cleveland Clinic Foundation, 9500 Euclid Avenue Desk F20, Cleveland, Ohio 44195, USA

${ }^{1}$ Patholgy and Laboratory Medicine Institute ${ }^{2}$ Department of Neurosurgery and the Neurological Institute, Rose Ella Burkhardt Brain Tumor and Neuro-Oncology Center, Cleveland Clinic, Cleveland, Ohio 44195, USA ${ }^{t} R J$ Weil is now at Department of Neurosurgery, Geisinger Health System, 100 North Academy Avenue, Danville, Pennsylvania, USA

\author{
Correspondence \\ should be addressed \\ to P C Johnston \\ Email \\ pcjohnston@doctors.org.uk
}

\section{Summary}

A 54-year-old woman presented with bi-temporal hemianopia, palpitations, and diaphoresis. An invasive pituitary macroadenoma was discovered. The patient had biochemical evidence of secondary hyperthyroidism and GH excess; however, she did not appear to be acromegalic. Surgical removal of the pituitary mass revealed a plurihormonal TSH/GH co-secreting pituitary adenoma. TSH-secreting adenomas can co-secrete other hormones including GH, prolactin, and gonadotropins; conversely, co-secretion of TSH from a pituitary adenoma in acromegaly is infrequent.

\section{Learning points:}

- This case highlights an unusual patient with a rare TSH/GH co-secreting pituitary adenoma with absence of the clinical features of acromegaly.

- Plurihormonality does not always translate into the clinical features of hormonal excess.

- There appears to be a clinical and immunohistochemical spectrum present in plurihormonal tumors.

\section{Background}

Thyrotropin (TSH)-secreting pituitary adenomas are rare and account for $1 \%$ or fewer of all pituitary adenomas. Approximately one-third of TSH-secreting pituitary adenomas co-secrete other hormones, the most common of which is growth hormone (GH) (16\%) followed by prolactin (11\%) and gonadotropins (1\%). Conversely, in GH-producing pituitary adenomas, $13 \%$ have been shown to demonstrate immunopositivity to TSH (1) (2). Plurihormonal pituitary tumors are either morphologically monomorphous (single cells producing different hormones) or plurimorphous (different cells producing different hormones). Plurihormonal pituitary tumors seem to predict a higher risk of tumor recurrence, in comparison to tumors that secrete only one hormone; therefore, careful follow-up of this population is essential (3) (4). This report describes a rare case of a TSH/GH co-secreting pituitary adenoma with the absence of features of acromegaly.

\section{Case presentation}

A 54-year-old woman was noted on a routine visit to her ophthalmologist to have bi-temporal hemianopia. 
Table 1 Pituitary hormonal profile at presentation.

\begin{tabular}{|c|c|c|}
\hline Test & Value & Normal range \\
\hline $\mathrm{fT}_{4}$ & 2.1 & $0.7-1.8 \mathrm{ng} / \mathrm{dl}$ \\
\hline $\mathrm{TSH}$ & 2.8 & $0.4-5.5 \mu \mathrm{U} / \mathrm{ml}$ \\
\hline $\mathrm{T}_{3}$ & 185 & 94-170 ng/dl \\
\hline Prolactin & 1.5 & $2.1-17.4 \mathrm{ng} / \mathrm{ml}$ \\
\hline GH (basal) & 1.58 & $0.01-0.97 \mathrm{ng} / \mathrm{ml}$ \\
\hline IGF1 & 747 & $87-267$ ng/ml \\
\hline Cortisol $^{a}$ & $6.6,24.1,15.8$ & $>18 \mu \mathrm{g} / \mathrm{dl}$ \\
\hline ACTH (am) & 16 & 8-42 pg/ml \\
\hline 24-h urine cortisol & 16.3 & $<45 \mu \mathrm{g} /$ day \\
\hline
\end{tabular}

$\mathrm{T}_{4}$, total thyroxine; $\mathrm{fT}_{4}$, free thyroxine; $\mathrm{TSH}$, thyroid-stimulating hormone; $\mathrm{T}_{3}$, tri-iodothyronine; $\mathrm{GH}$, growth hormone; IGF1, insulin-like growth factor 1; ACTH, adrenocorticotropic hormone.

a Short synacthen test: serum cortisol at baseline, +30 , and $+60 \mathrm{~min}$ respectively after administration of $250 \mu \mathrm{g}$ cosyntropin.

She had reported difficulty with reading, but had not noted peripheral vision loss. Her medical history included atrial fibrillation, hypertension, cardiomyopathy, and sleep apnea. On review of symptoms, she reported hirsutism, feeling 'hot', palpitations, and diaphoresis. Physical examination revealed an obese woman with a BMI of 44, hirsutism, a moon-shaped face, and supraclavicular fullness. She had no goiter or dysthyroid eye disease. She had no overt features of acromegaly such as coarse facial features or broad fingers.

\section{Investigation}

Bi-temporal hemianopia was present, and magnetic resonance imaging (MRI) of the sella revealed a large pituitary macroadenoma measuring $2.3 \mathrm{~cm}$ and left cavernous sinus invasion, with suprasellar extension compressing the optic chiasm, principally to the left of midline. Initial laboratory testing revealed central hyperthyroidism: thyroxine $\left(\mathrm{T}_{4}\right)$ $11.4(5.0-11.0 \mu \mathrm{g} / \mathrm{dl})$, free thyroxine $\left(\mathrm{fT}_{4}\right) 2.1(0.7-$ $1.8 \mathrm{ng} / \mathrm{dl})$, TSH $2.8(0.4-5.5 \mu \mathrm{U} / \mathrm{ml})$, and tri-iodothyronine $\left(\mathrm{T}_{3}\right) 185(94-170 \mathrm{ng} / \mathrm{dl})$, in addition to hypersomatotropism: insulin-like growth factor 1 (IGF1) 747 $(87-267 \mathrm{ng} / \mathrm{ml})$ and GH $1.58 \mathrm{ng} / \mathrm{ml}$ (Table 1).

\section{Treatment}

In the context of the initial biochemistry indicating a plurihormonal TSH/GH co-secreting pituitary adenoma, pre-operative treatment with methimazole and octreotide was initiated. She proceeded to transsphenoidal resection of the pituitary macroadenoma 2 weeks later, following a reduction in her diaphoresis, hot flashes, and palpitations. At surgery, a sellar and suprasellar tumor was removed; the diaphragma sella was identified, ballotted down into the sellar region with the pulsations of the cerebrospinal fluid when the tumor was removed, and there was no dehiscence of the diaphragm or transgression of it by tumor identified upon careful inspection after tumor resection; it was believed that a gross total resection was effected. The normal pituitary gland, which was displaced superiorly and to the right, was thin and atretic. Immunohistochemical staining of the adenoma with antibodies to adrenocorticotropic hormone (ACTH), GH, follicle-stimulating hormone, luteinizing hormone, prolactin (PRL), and TSH was performed. Immunoreactivity with antibody directed against GH was strong and diffuse, while that of TSH was exceptionally rare and scattered throughout the adenoma (Fig. 1A, GH and B, TSH, show representative staining; positive cells are brown). The adenoma did not stain with any of the other abovementioned antibodies. Methimazole and octreotide were stopped on the day of surgery. Post-operatively, the symptoms and signs of hyperthyroidism resolved rapidly.

\section{Outcome and follow-up}

Three weeks later, she reported recrudescence of symptoms of hyperthyroidism (diaphoresis and palpitations), with recurrent evidence of biochemical hyperthyroidism and GH excess; methimazole and octreotide were re-introduced and 2 weeks later thyroid function normalized, $\mathrm{T}_{4} 10.2(5.0-11.0 \mu \mathrm{g} / \mathrm{dl})$ and TSH $4.9(0.4-5.5 \mu \mathrm{U} / \mathrm{ml})$. Residual adenomatous tissue was present on sellar imaging
A

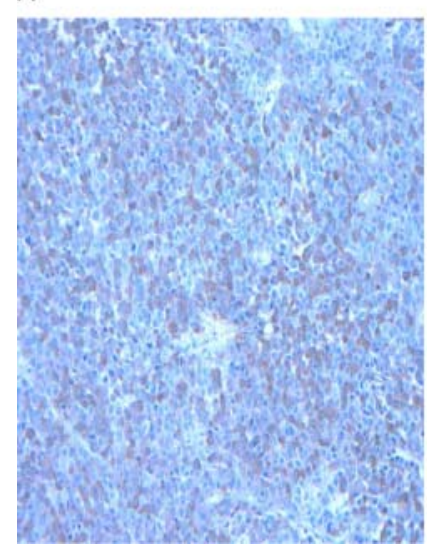

B

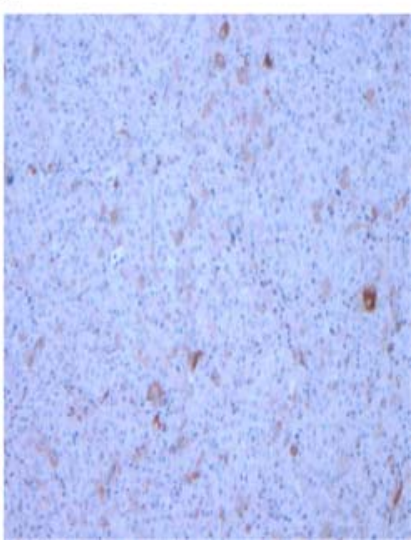

\section{Figure 1}

Immunohistochemical staining results. (A) The adenoma shows diffuse staining for antibody againt growth hormone (GH). (B) There is sparse and much weaker staining for antibody directed against TSH. Positively staining cells are brown. 
A

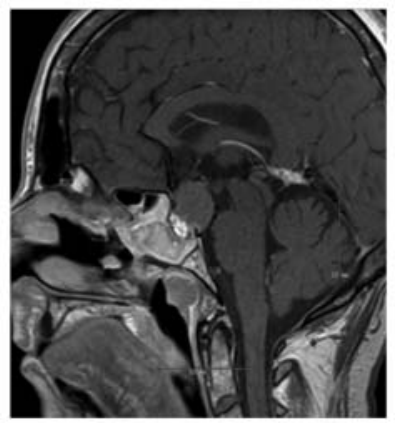

B

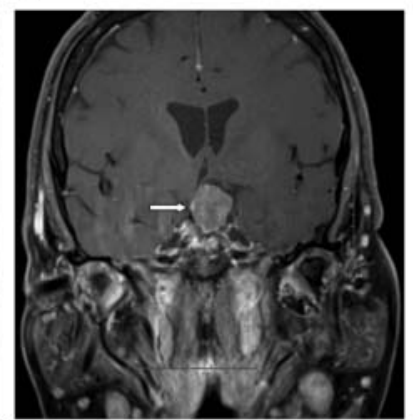

c

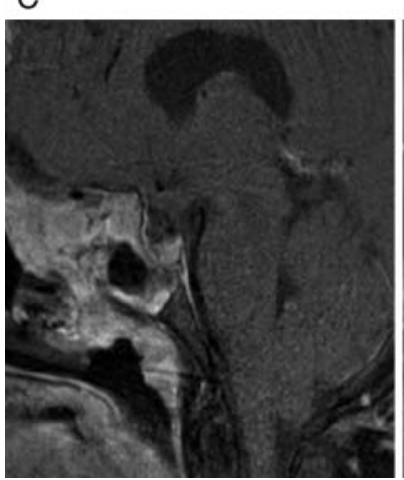

D

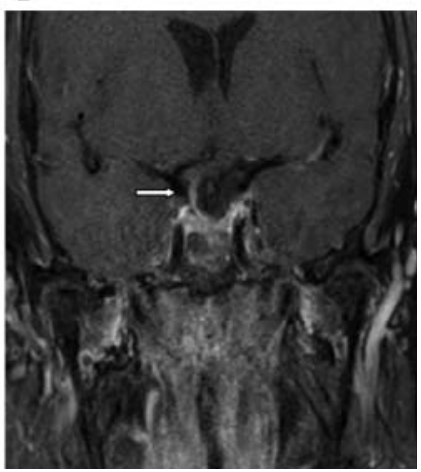

Figure 2

Magentic resonance imaging results. ( $A$ and $B$ ) T1-weighted, postgadolinium coronal (A) and sagittal (B) images demonstrating a large pituitary macroadenoma (arrow) present on sellar imaging 6 weeks after the initial surgery; a fat graft (with very high signal intensity) lies in the floor of the sella just anteroinferior to the compressed normal gland (best observed on the coronal view, A). The normal gland, lying in the floor of the enlarged sella, enhances avidly and is compressed by the suprasellar tumor, as best appreciated on the sagittal view. The tumor was suprasellar, above the diaphragm as observed at surgery, and compressed the diaphragm; the infundibulum is compressed and distorted to the right of the tumor and enhances more than the tumor itself (the arrow in B identifies the stalk as it passes to the compressed pituitary in the floor of the sella). (C and D) T1-weighted, post-gadolinium coronal and sagittal images 6 weeks after the second transsphenoidal surgery, with complete resection of the suprasellar, intracranial component of tumor. The infundibulum is now more easily identified, although still deviated to the right (arrow in D). The normal pituitary gland has expanded to fill more of the sella (best appreciated on the sagittal view, C).

(Fig. 2A and B); the tumor appeared to have descended from the suprasellar space into the enlarged sella, sitting above and distorting the infundibulum and compressing the normal gland, both of which enhanced briskly. Repeat, extended transsphenoidal surgery was undertaken. At surgery, the residual tumor was located wholly above the diaphragm sella, which was intact; an extended, transsphenoidal, suprasellar approach, passing above the sella and pituitary and then approaching the tumor from above the diaphragm, was needed to identify and resect the tumor in the suprasellar space; the infundibulum was

identified in the suprasellar, intracranial space, displaced to the right by the tumor, and then identified passing through the diaphragm, to the normal gland within the sella; it was left undisturbed (Fig. 2B). Methimazole and octreotide were discontinued again on the day of surgery. Repeat immunohistochemistry of the resected tissue was identical to the initial histological findings. Ki-67 was 2.1 and $<5 \%$ of adenoma cells were p53 positive. Normalization of thyroid function and GH levels was observed post-operatively and has persisted, with complete resolution of the hyperthyroidism (Table 2). Post-operative MRI performed 6 weeks after surgery confirmed gross total resection of the intracranial component of the tumor; the infundibulum remained distorted to the right and is well visualized (Fig. 2C and D). At most recent follow-up, 3 years after the initial pituitary surgery, she has residual sleep apnea and continues to use 'C-PAP' nightly but is otherwise endocrinologically and neurologically normal.

\section{Discussion}

Plurihormonality does not always translate into the clinical features of hormonal excess. In addition to being distinct from one another with varying degrees of prominence, the clinical signs of hyperthyroidism and acromegaly can overlap. Patients with thyrotropic and somatotropic adenomas tend to present when the adenomas are large and frequently can be invasive and less amenable to surgical cure. Cure rates after surgery have been reported in around a third of patients with invasive tumors (5). Pre-operative somatostatin analog treatment can reduce tumor size and control thyroid and GH hypersecretion. Further options after surgery include radiotherapy and/or somatostatin analogs. Somatostatin analogs have been shown to result in euthyroidism in most cases of thyrotropinomas and $\sim 50 \%$ achieve a reduction in pituitary mass size; dopamine agonists have also been used, but with more limited success in thyrotropinomas (6) (7).

In our case, the predominant symptoms were those of hyperthyroidism, although the clinical signs of hypertension, cardiomyopathy, and sleep apnea could be a clinical manifestation of acromegaly or morbid obesity as well. Interestingly, immunohistochemistry with antibodies directed against TSH showed rare and sparse positive cells. In contrast, although IGF1 levels elevated to approximately three-times normal and showed diffuse robust staining against $\mathrm{GH}$ in the adenoma, the patient did not exhibit signs of acromegaly. One explanation is that the associated 'classic' signs often lag behind the 
Table 2 Serial thyroid function, GF1 and GH levels over time.

\begin{tabular}{lll}
\hline Test & & Presentation \\
\cline { 1 - 1 } $\mathrm{T}_{4}(\mu \mathrm{g} / \mathrm{dl})$ & 11.4 \\
$\mathrm{TSH}(\mu \mathrm{U} / \mathrm{ml})$ & 2.8 \\
$\mathrm{~T}_{3}(\mathrm{ng} / \mathrm{dl})$ & 185 \\
$\mathrm{GH}(\mathrm{ng} / \mathrm{ml})$ & 1.58 \\
$\mathrm{IGF} 1(\mathrm{ng} / \mathrm{ml})$ & 747 \\
\hline
\end{tabular}

\begin{tabular}{l}
\hline $\begin{array}{l}\text { Day 1-post-op } \\
\text { (first TSS) }\end{array}$ \\
\hline 12.9 \\
3.7 \\
215 \\
2.34 \\
471 \\
\hline
\end{tabular}

\begin{tabular}{l}
\hline $\begin{array}{l}\text { Day 5-post-op } \\
\text { (second TSS) }\end{array}$ \\
\hline 2.8 \\
0.04 \\
32 \\
0.2 \\
138 \\
\hline
\end{tabular}

\begin{tabular}{l}
$\begin{array}{l}\text { Follow-up } \\
\text { (7 months) }\end{array}$ \\
\hline 6.6 \\
1.2 \\
96 \\
$<0.05$ \\
120 \\
\hline
\end{tabular}

\begin{tabular}{l} 
Normal range \\
\hline $5-11$ \\
$0.4-5.5$ \\
$94-170$ \\
$0.01-0.97$ \\
$87-267$ \\
\hline
\end{tabular}

TSS, transsphenoidal surgery; $\mathrm{T}_{4}$, total thyroxine; TSH, thyroid-stimulating hormone; $\mathrm{T}_{3}$, tri-iodothyronine; $\mathrm{GH}$, growth hormone; IGF1, insulin-like growth factor 1.

elevation of IGF1/GH. Another plausible explanation would be that even though the pituitary macroadenoma has been present for some time as indicated by its size (8), production of excessive somatotropins from the adenoma could have been a recent phenomenon. Secretion of GH with low bioactivity from a 'silent' somatotrope adenoma could also explain the relative absence of the clinical signs of acromegaly (9). Not all cases of biochemical and clinical TSH/GH co-secreting pituitary adenomas display immunopositivity to TSH and/or GH. Negative immunostaining for TSH in co-secretory TSH/GH adenomas has been demonstrated, which could be due simply to low TSH levels in the adenoma (10). There appears to be a clinical and immunohistochemical spectrum present in plurihormonal tumors, and electron microscopy has been utilized by some to evaluate tumor cell lines in experimental animals (11). De novo transformation of a thyrotropinoma to a thyro-somatotrope adenoma appears to be exceedingly rare. The only case reported arose in a patient with hyperthyroidism from a thyrotropinoma, who developed evidence of GH co-secretion only after treatment with octreotide for 1 year. The authors speculated that a series of genetic mutations resulted in transformation of a monoclonal adenoma to a plurihormonal tumor (12). The PIT1 protein, which is a transcription factor whose presence is required in utero for normal development of the mammosomatropes that produce GH and PRL, is also required for the maintenance of normal expression of $\mathrm{GH}$, prolactin, and TSH after the separate embryonic origin of thryotropes and has been postulated to play a role in the development of co-secretory pituitary adenomas (13). A recent study has demonstrated that the degree of $\beta$-TSH immunoreactivity appears to be associated with the degree of hyperthyroidism (14).

In summary, this case highlights an unusual patient with a rare TSH/GH co-secreting pituitary adenoma in whom symptomatic hyperthyroidism was the dominant and only clinical feature, without acromegaly. Immunohistochemistry was positive for GH but only rarely and sparsely positive for TSH. Secondly, while the patient had symptomatic relief of the signs and symptoms of hyperthyroidism for several weeks after what was thought to be gross total resection of a macroadenoma delimited by an elevated but anatomically intact diaphragm sella, the rapid recrudescence of hyperthyroidism led to early reappraisal and identification of residual component of tumor located wholly within the supra-diaphragmatic, intracranial space. Resection of the invasive, intracranial component of the adenoma led to resolution of biochemical evidence of acromegaly and the patient's clinical hyperthyroidism.

\section{Declaration of interest}

The authors declare that there is no conflict of interest that could be perceived as prejudicing the impartiality of the research reported.

\section{Funding}

This research did not receive any specific grant from any funding agency in the public, commercial or not-for-profit sector.

Author contribution statement

All authors were involved in the preparation and writing of the manuscript.

\section{References}

1 Beck-Peccoz P, Brucker-Davis F, Persani L, Smallridge RC \& Weintraub BD 1996 Thyrotropin secreting pituitary tumours. Endocrine Reviews 17 610-638.

2 Skoric T, Korsić M, Zarković K, Plavsic V, Besenski N, Breskovac L, Giljevic Z \& Paladino J 1999 Clinical and morphological features of undifferentiated monomorphous GH/TSH-secreting pituitary adenoma. European Journal of Endocrinology 140 528-537. (doi:10.1530/eje. 0.1400528 )

3 Malchiodi E, Profka E, Ferrante E, Sala E, Verrua E, Campi I, Lania AG, Arosio M, Locatelli M, Mortini P et al. 2014 Thyrotropin-secreting pituitary adenomas: outcome of pituitary surgery and irradiation. Journal of Clinical Endocrinology and Metabolism 99 2069-2076. (doi:10.1210/jc.2013-4376) 
4 Kovaks K, Horvath E, Asa SL, Stefaneanu L \& Sano T 1989 Pituitary cells producing more than one hormone human pituitary adenomas. Trends in Endocrinology and Metabolism 1 104-107. (doi:10.1016/10432760(89)90012-X)

5 Losa M, Giovanelli M, Persani L, Mortini P, Faglia G \& Beck-Peccoz P 1996 Criteria of cure and follow up of central hyperthyroidism due to thyrotropin secreting pituitary adenomas. Journal of Clinical Endocrinology and Metabolism 81 3084-3090.

6 Caron P, Arlot S, Bauters C, Chanson P, Kuhn JM, Pugeat M, Marechaud R, Teutsch C, Vidal E \& Sassano P 2001 Efficacy of the long acting octreotide formulation (octreotide-LAR) in patients with thyrotropin-secreting pituitary adenomas. Journal of Clinical Endocrinology and Metabolism 86 2849-2853. (doi:10.1210/jcem.86.6. 7593)

7 Hirasawa R, Hashimoto K, Makino S, Suemaru S, Takao T, Ota Z, Hoshida Y, Yoshino T \& Akagi T 1991 Effect of a long acting somatostsin analogue (SMS 201-995) on a growth hormone and thyroid stimulating hormone producing pituitary tumour. Acta Medicinae Okayama $\mathbf{4 5}$ 107-115.

8 Ozawa Y, Kameya T, Kasuga A, Naritaka H, Kanda N, Maruyama H \& Saruta T 1998 A functional thyrotropin and growth hormone secreting pituitary adenoma with an ultrastructurally monomorphic feature a case study. Endocrine Journal 45 211-219. (doi:10.1507/ endocrj.45.211)
9 Gołkowski F, Buziak-Bereza M, Stefańska A, Trofimiuk M, Pantofliński J, Huszno B, Czepko R \& Adamek D 2006 A case of GH and TSH secreting pituitary macroadenoma. Przeglad Lekarski 63 106-108.

10 Koide Y, Kugai N, Kimura S, Fujita T, Kameya T, Azukizawa M, Ogata E, Tomono Y \& Yamashita K 1982 A case of pituitary adenoma with possible simultaneous secretion of thyrotropin and follicle stimulating hormone. Journal of Clinical Endocrinology and Metabolism 54 397-403. (doi:10.1210/jcem-54-2-397)

11 Radian S, Coculescu M \& Morris JF 2003 Somatotroph to thyrotroph cell transdifferentation during experimental hypothyroidism - a light and electron microscopy study. Journal of Cellular and Molecular Medicine 7 297-306. (doi:10.1111/j.1582-4934.2003.tb00230.x)

12 Glynn N \& Agha A 2013 Unexpected clinical course during treatment of a TSH-secreting pituitary adenoma. Endocrine Practice 19 88-91. (doi:10.4158/EP13036.CR)

13 Simmons DM, Voss JW, Ingraham HA, Holloway JM, Broide RS, Rosenfeld MG \& Swanson LW 1990 Pituitary cell phenotypes involve cell specific Pit-1 mRNA translation and syngergistic interactions with other transcription factors. Genes and Development 4 695-711. (doi:10.1101/gad.4.5.695)

14 Tritos NA, Eppakayala S, Swearingen B, Hedley-Whyte ET, Miller KK, Nachtigall LB, Grinspoon SK, Biller BM \& Klibanski A 2013 Pathologic and clinical features of pituitary adenomas showing TSH immunoreactivity. Pituitary 16 287-293. (doi:10.1007/s11102-012-0419-3)

Received in final form 10 September 2014

Accepted 11 December 2014 